\title{
Characterization of a Gallibacterium Genomospecies 2 Hemagglutinin
}

\author{
${ }^{1}$ S. Ramirez-Apolinar, ${ }^{2,3}$ Fernando M. Guerra-Infante, ${ }^{2}$ Maria de J. de Haro-Cruz, \\ ${ }^{1}$ C. Salgado-Miranda, ${ }^{4}$ E. Madrid-Morales, ${ }^{5}$ B.M. Kristensen, ${ }^{5}$ A.M. Bojesen, \\ ${ }^{6} \mathrm{E}$. Negrete-Abascal and ${ }^{1} \mathrm{E}$. Soriano-Vargas \\ ${ }^{1}$ Centro de Investigacion y Estudios Avanzados en Salud Animal, \\ Facultad de Medicina Veterinaria y Zootecnia, \\ Universidad Autonoma del Estado de Mexico, 50200 Toluca, Mexico \\ ${ }^{2}$ Departamento de Microbiologia Veterinaria, Escuela Nacional de Ciencias Biologicas, \\ Instituto Politecnico Nacional, 11340 D.F., Mexico \\ ${ }^{3}$ Laboratorio de Bioinmunologia Molecular del Instituto Nacional de Perinatologia, 11000 D.F., Mexico \\ ${ }^{4}$ Centro Conjunto de Investigacion en Quimica Sustentable UAEM-UNAM, 50200 Toluca, Mexico \\ ${ }^{5}$ Department of Veterinary Disease Biology, Faculty of Life Science, \\ University of Copenhagen, DK-1870 Frederiksberg C, Denmark \\ ${ }^{6}$ Carrera de Biologia, Facultad de Estudios Superiores Iztacala, \\ Universidad Nacional Autonoma de Mexico, 54090 Tlanepantla, Mexico
}

\begin{abstract}
The hemagglutinin of Gallibacterium genomospecies 2 strain CCM 5976 was purified by affinity to Glutaraldehyde-Fixed Rabbit Erythrocytes (GFRE) using trypsin-treated bacteria. Two protein bands of approximately 23 and $26 \mathrm{kDa}$ were consistently observed using $12 \%$ SDS-PAGE. Other protein bands were also associated to GFRE but disappeared when heated up to $120^{\circ} \mathrm{C}$ while the hemagglutinating activity remained. Hemagglutinating activity by Gallibacterium was not inhibited by mannose or other carbohydrates tested yet both proteins and carbohydrates were consistently found in samples of purified hemagglutinin. These findings suggest that the Gallibacterium genomospecies 2 hemagglutinin is a glycoprotein-like molecule consisting of at least two subunits of 23 and $26 \mathrm{kDa}$ and that are thermostable, trypsin-resistant and mannose-resistant.
\end{abstract}

Key words: Gallibacterium, hemagglutinin, chicken, GFRE, Mexico

\section{INTRODUCTION}

The Gallibacterium genus belong to the Pasteurellaceae family and includes bacteria of avian origin previously reported as avian Pasteurella haemolytica, Actinobacillus salpingitidis, P. anatis, taxon 2 and 3 complex of Bisgaard. Currently, the genus includes four named species and three genomospecies (Christensen et al., 2003; Bisgaard et al., 2009). Gallibacterium anatis biovar haemolytica has been associated with egg production drop in layer flocks due to reproductive disorders in hens (Neubauer et al., 2009). The bacterium has been associated to pathological lesions including salpingitis, peritonitis, septicemia, pericarditis, hepatitis, enteritis and respiratory tract lesions (Bisgaard, 1993) but has also been considered as part of normal upper respiratory and lower reproductive tract flora of chickens (Bisgaard, 1977). Recently, it was determined that Gallibacterium genomospecies 2, strain CCM 5976 is capable of causing primary infection in chickens underlining its pathogenic potential (Zepeda et al., 2010). Previous studies have demonstrated that this strain has hemagglutinating activity and is capable to adhere to tracheal and oviduct epithelial cells of hens (Ramirez et al., 2007; Zepeda et al., 2009) which support the idea that the strain CCM 5976 has one or more adhesins allowing it to adhere to host epithelial cells. Among members of Pasteurellaceae, a variety of adhesins such as fimbriae, fibrils, outer membrane proteins, lipooligosaccharides, lipopolysaccharides and capsular polysaccharides have been described (Jacques and Paradis, 1998) however, the adhesin through which Gallibacterium adheres to eukaryotic cells is unknown. The purpose of the present study was to purify and characterize the hemagglutinin of the strain CCM 5976 of Gallibacterium genomospecies 2.

Corresponding Author: S. Ramirez-Apolinar, Centro de Investigacion y Estudios Avanzados en Salud Animal, Facultad de Medicina Veterinaria y Zootecnia, Universidad Autonoma del Estado de Mexico. Carretera Panamericana Toluca-Atlacomulco km 15.5, 50200 Toluca, Mexico 


\section{MATERIALS AND METHODS}

Bacterial strain: The well-characterized reference strain CCM 5976 of G. genomospecies 2, obtained from a chicken oviduct with salpingitis was included in the study (Christensen et al., 2003; Zepeda et al., 2009, 2010).

Media: The bacteria were cultivated on $10 \%$ sheep blood agar (BD Bioxon, Becton Dickinson, Cuautitlan Izcalli, Mexico, Mexico) at $37^{\circ} \mathrm{C}$ and incubated overnight in a candle jar. Brain-heart infusion broth (BD Bioxon) was used for propagation of bacterial cultures. For improved growth, this medium was supplemented with $1 \%(\mathrm{v} / \mathrm{v})$ filter-sterilized, heat-inactivated horse serum (BIOCEL, Zapopan, Jalisco, Mexico) as described previously (Zepeda et al., 2009, 2010).

Rabbit erythrocytes: Glutaraldehyde-fixed rabbit erythrocytes were prepared as described previously (Soriano et al., 2001). Briefly, rabbit blood was collected and mixed with Alsever's solution. The erythrocytes were harvested by centrifugation and washed three times in $0.15 \mathrm{M} \mathrm{NaCl}$. A $1 \%$ glutaraldehyde solution was prepared by dilution with a solution containing $0.01 \mathrm{M} \mathrm{Na}_{3} \mathrm{PO}_{4}(\mathrm{pH}$ 8.2 ) (1 volume) and $0.15 \mathrm{M} \mathrm{NaCl}$ ( 9 volumes) in distilled water ( 5 volumes). A $1 \%$ erythrocytes suspension was prepared in the $1 \%$ glutaraldehyde solution and held at $4^{\circ} \mathrm{C}$ for $30 \mathrm{~min}$. Fixed-erythrocytes were centrifuged, washed 5 times with $0.15 \mathrm{M} \mathrm{NaCl}$ and suspended in distilled water. A $0.01 \%(\mathrm{w} / \mathrm{v})$ thimerosal was added and the suspension was stored at $4^{\circ} \mathrm{C}$.

Hemagglutinin purification: Bacteria grown on 10\% sheep blood agar were harvested in PBS pH 7.2 and washed 3 times by centrifugation. The bacterial suspension was treated with $0.25 \%$ trypsin (Sigma, St. Louis, MO) and incubated at $37^{\circ} \mathrm{C}$ for 45 min with shaking (Iritani and Hidaka, 1976). The bacterial suspension was centrifuged at $8000 \times \mathrm{g}$ for $10 \mathrm{~min}$ and supernatant was collected, the trypsin activity was blocked with $1 \%$ of proteases inhibitor solution $(0.06 \mathrm{M}$ PhenylmethySulfonyl Fluoride in isopropanol [PMSF; Boehringer, Mannheim]). A volume of $5 \%$ of GFRE was added to the supernatant and incubated at $37^{\circ} \mathrm{C}$ for $35 \mathrm{~min}$. The GFRE was collected and washed 3 times with PBS by centrifugation. The GFRE was mixed with a glycine buffer $(0.4 \mathrm{M}) \mathrm{pH} 2.8$ and incubated at $37^{\circ} \mathrm{C}$ overnight. Supernatant was separated by centrifugation and concentrated using a centrifugal vacuum concentrator (Vacufuge Plus, Eppendorf) at $45^{\circ} \mathrm{C}$ and this concentrate was termed purified hemagglutinin.
Hemagglutination test: The hemagglutinating titers were determined by performing the assays in 96 well micro-titer plates. A volume of $50 \mu \mathrm{L}$ of purified hemagglutinin sample was 2 fold serial diluted in PBS and $50 \mu \mathrm{L}$ of $1 \%$ GFRE was added. The hemagglutinating titer was the reciprocal of the highest dilution of antigen showing complete agglutination of the erythrocytes after incubation for $30 \mathrm{~min}$ at room temperature (Soriano et al., 2001).

Sodium Dodesyl Sulfate-Polyacrylamide Gel Electrophoresis (SDS-PAGE): SDS-PAGE analysis was carried out as previously described by Laemmli (1970). Briefly, a volume of $20 \mu \mathrm{L}$ of purified hemagglutinin solution containing 8 hemagglutinin units was mixed with $5 \mu \mathrm{L}$ of loading buffer $(0.5 \mathrm{M}$ tris, $\mathrm{pH} 6.8 ; 10 \%$ SDS, glycerol and bromophenol blue as the dye) in the absence or presence of $1 \%$ reducing agent (dithiothreitol). The proteins were resolved in $12 \%$ SDS-PAGE and the gels were stained with Coomassie brilliant blue.

Effect of carbohydrates on the hemagglutinating activity: The effect of carbohydrates on the hemagglutinating activity of the purified hemagglutinin was determined as reported elsewhere (Iritani et al., 1981). Briefly, $50 \mu \mathrm{L}$ of purified hemagglutinin sample containing one hemagglutinin unit was mixed with an equal volume of $1 \%$ solution of the relevant carbohydrate (Fucose, galactose, galactosamine, $\mathrm{N}$-acetyl glucosamine, mannose, glucose, xylose, salicin, sucrose and sorbitol) and incubated at $37^{\circ} \mathrm{C}$ for $15 \mathrm{~min}$. After this, $50 \mu \mathrm{L}$ of $1 \%$ GFRE were added after incubation and the hemagglutinin activity was recorded $1 \mathrm{~h}$ later. Assays were carried out in triplicate.

Heat treatment: To determine the influence of temperature on hemagglutinating activity of Gallibacterium, $50 \mu \mathrm{L}$ volumes of purified hemagglutinin solution containing eight hemagglutinin units were heated for $30 \mathrm{~min}$ at 37,50 , 60,80 and $96^{\circ} \mathrm{C}$ and $15 \mathrm{~min}$ at $120^{\circ} \mathrm{C}$ (Jaramillo et al., 2000). Subsequently, hemagglutination assays were performed as mentioned before.

Protein and carbohydrate determination: Protein concentrations were estimated by the Bradford assay using bovine serum albumin as the standard and the total sugar content was estimated by the Phenol-Sulfuric Acid Method using glucose as the standard (Mikcha et al., 2006). The assays were carried out in triplicate.

\section{RESULTS AND DISCUSSION}

The hemagglutinin purification method resulted in five bands of approximately $9.1,23,26,36.6$ and $47.5 \mathrm{kDa}$ 


\section{J. Anim. Vet. Adv., 11 (4): 556-560, 2012}

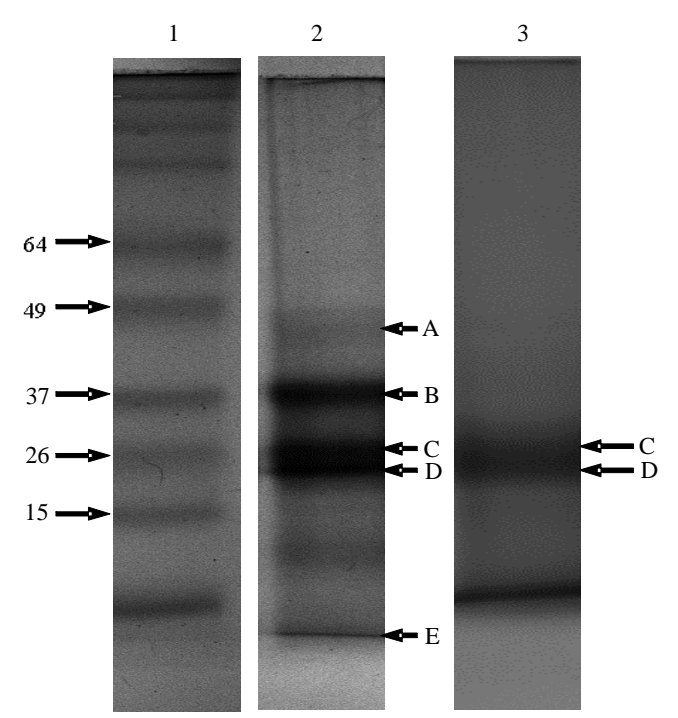

Fig. 1: Coomassie brilliant blue stained SDS-PAGE showing purified hemagglutinin of Gallibacterium genomospecies 2 strain CCM 5976. Line 1, molecular size marker $(\mathrm{kDa})$; line 2 , sample without heat-treatment; line 3 , sample with heat-treatment. Each sample contained 8 hemagglutinin units. Letters on line 2 and 3 indicates the bands obtained without or with heat treatment, respectively A, $47.5 \mathrm{kDa}$;, $36.6 \mathrm{kDa} ; \mathrm{C}, 26 \mathrm{kDa}$; $\mathrm{D}, 23 \mathrm{kDa}$ and $\mathrm{E}, 9.1 \mathrm{kDa}$

as separated by SDS-PAGE. The protein bands of 23,26 and $36.6 \mathrm{kDa}$ were the most abundant (Fig. 1). No differences were observed in the purified sample profile with or without reducing agent. The different tested carbohydrates including mannose did not inhibit the hemagglutinating activity of the purified hemagglutinin.

The hemagglutinating activity was retained after heat treatment up to $120^{\circ} \mathrm{C}$ for $15 \mathrm{~min}$ showing no decrease in hemagglutinating titers. Furthermore, the proteins bands of 23 and $26 \mathrm{kDa}$ were still present whereas the remaining three protein bands disappeared (Fig. 1). The total protein/carbohydrates contents of purified hemagglutinin samples were approximately $50 \%$ as determined by the phenol-sulfuric acid method with 62.3 and $48 \mu \mathrm{g} \mathrm{mL} \mathrm{m}^{-1}$ of protein and total carbohydrates contents, respectively. The ability of pathogenic bacteria to adhere depends on the expression of adhesive molecules or structures named adhesins which attach to receptors on the host mucosal surface (Jacques and Paradis, 1998). The bacterial adhesins may also agglutinate red blood cells of some animal species and these adhesins, termed hemagglutinins are important in avian respiratory tract infections promoted by for example, Avibacterium paragallinarum (Yamaguchi et al., 1993), Escherichia coli (Maurer et al.,
1998) and Bordetella avium (Temple et al., 1998). A wide variety of adhesins from members of the Pasteurellaceae family have been characterized (Jacques and Paradis, 1998) however, this is the first report on purification and characterization of hemagglutinins from a member of the Allibacterium genus, represented by G. genomospecies 2 strain CCM 5976.

In this study, two proteins bands of around 23 and $26 \mathrm{kDa}$ were consistently identified by SDS-PAGE. In addition, three proteins of $9.1,36.6$ and $47.5 \mathrm{kDa}$, respectively associated with GFRE were identified. However, these protein bands were not detected in samples heated to $120^{\circ} \mathrm{C}$ for $15 \mathrm{~min}$ although, showing intact hemagglutinating activity thus, indicating that these three proteins are not required for the hemagglutination. Other g-negative bacteria express outer membrane proteins or surface exposed glycoproteins with hemagglutinating activity that are thermostable at high temperatures and involved in bacterial adhesion to HeLa, human colon adenocarcinoma and Hep-2 cells (Lutwyche et al., 1994; Mikcha et al., 2006; Rocha-De-Souza et al., 2001).

The different carbohydrates used in this study did not inhibit the hemagglutinating activity. However, this result does not exclude the involvement of sugar moieties in the hemagglutinin-erythrocyte interaction since, alternative disaccharides, monosaccharides or polysaccharides might inhibit the hemagglutination. Similarly, some adhesins (Glycoprotein or lipopolysaccharide) identified in other bacteria were only inhibited by porcine or bovine mucin, thiroglobulin, fetuin, asialofetuin and laminin (Alam et al., 1996; Meng et al., 1998; Sarrn et al., 1999). However, none of these potential inhibitors were tested in the current study. The protein bands of 23 and $26 \mathrm{kDa}$ did not seem to undergo conformational changes affecting their activity when heated in the presence of SDS or dithiothreitol.

This is unlike the Outer Membrane Proteins (OMPs) previously reported from members of Pasteurellaceae family which are heat-modifiable (Beher et al., 1980; Blackall et al., 1990). Beher et al. (1980) obtained the smallest molecular weight protein bands of OMPs from treating samples with trypsin compared to samples heated at $100^{\circ} \mathrm{C}$, this fact likely explains the finding of trypsin treated hemagglutinins that did not modify further despite high temperature treatment.

\section{CONCLUSION}

Researchers have identified a glycoprotein-like hemagglutinin in Gallibacterium genomospecies 2, strain CCM 5976 which is constituted by two subunits of 23 and $26 \mathrm{kDa}$, respectively. The hemagglutinin is thermostable, mannose-resistant, trypsin-resistant and likely located in the outer membrane. Due to the selective purification 
method performed in this study, the presence of other hemagglutinins in Gallibacterium cannot be ruled out and further studies are needed to clarify the adhesins involvement in hemagglutination and their role in adhesion to epithelial cells of chickens.

\section{ACKNOWLEDGEMENTS}

Saul Ramirez-Apolinar was supported by Consejo Nacional de Ciencia y Tecnologia (CONACyT), Mexico. This research was funded by the Universidad Autonoma del Estado de Mexico, project 2732/2008U.

\section{REFERENCES}

Alam, M., S.I. Miyoshi, K.I. Tomochika and S. Shinoda, 1996. Purification and characterization of novel hemagglutinins from Vibrio mimicus: A 39-kilodalton major outer membrane protein and lipopolysaccharide. Infect. Immunity, 64: 4035-4041.

Beher, M.G., C.A. Schnaitman and A.P. Pugsley, 1980. Major heat-modifiable outer membrane protein in gram-negative bacteria: Comparison with the OmpA protein of Escherichia coli. J. Bacteriol., 143: 906-913.

Bisgaard, M., 1977. Incidence of Pasteurella haemolytica in the respiratory tract of apparently healthy chickens and chickens with infectious bronchitis. Characterisation of 213 strains. Avian Pathol., 6: 285-292.

Bisgaard, M., 1993. Ecology and significance of Pasteurellaceae in animals. Zentbl. Bakteriol., 279: 7-26.

Bisgaard, M., B.M. Korczak, H.J. Busse, P.K.A.M. Bojesen and H. Christensen, 2009. Classification of the taxon 2 and taxon 3 complex of Bisgaard within Gallibacterium and description of Gallibacterium melopsittaci sp. nov., Gallibacterium trehalosifermentans sp. nov. and Gallibacterium salpingitidis sp. nov. Int. J. Syst. Evol. Microbiol., 59: 735-744.

Blackall, P.J., D.G. Rogers and R. Yamamoto, 1990. Outermembrane proteins of Haemophilus paragallinarum. Avian Dis., 34: 871-877.

Christensen, H., M.B.A.M. Bojesen, R. Mutters and J.E. Olsen, 2003. Genetic relationships among avian isolates classified as Pasteurella haemolytica, Actinobacillus salpingitidis or Pasteurella anatis with proposal of Gallibacterium anatis gen. nov., comb. nov. and description of additional genomospecies within Gallibacterium gen. nov. Int. J. Syst. Evol. Microbiol., 53: 275-287.
Iritani, Y. and S. Hidaka, 1976. Enhancement of hemagglutinating activity of Haemophilus gallinarum by trypsin. Avian Dis., 20: 614-616.

Iritani, Y., T. Yamaguchi, K. Katagiri and H. Arita, 1981. Hemagglutination inhibition of Haemophilus paragallinarum type 1 hemagglutinin by lipopolysaccharide. Am. J. Vet. Res., 42: 689-690.

Jacques, M. and S.E. Paradis, 1998. Adhesin-receptor interactions in Pasteurellaceae. FEMS Microbiol. Rev., 22: 45-49.

Jaramillo, L., F. Diaz, P. Hernandez, H. Debray, F. Trigo, G. Mendoza and E. Zenteno, 2000. Purification and characterization of an adhesin from Pasteurella haemolytica. Glycobiol., 10: 31-37.

Laemmli, U.K., 1970. Cleavage of structural proteins during the assembly of the head of bacteriophage T4. Nature, 227: 680-685.

Lutwyche, P., R. Rupps, J. Cavanagh, R.A. Warren and D.E. Brooks, 1994. Cloning, sequencing and viscometric adhesion analysis of heat-resistant agglutinin 1, an integral membrane hemagglutinin from Escherichia coli O9:H10:K99. Infect. Immunity, 62: 5020-5026.

Maurer, J.J., T.P. Brown, W.L. Steffens and S.G. Thayer, 1998. The occurrence of ambient temperatureregulated adhesins, curli and the temperaturesensitive hemagglutinin tsh among avian Escherichia coli. Avian Dis., 42: 106-118.

Meng, Q., M.S. Kerley, T.J. Russel and G.L. Allee, 1998. Lectin-like activity of Escherichia coli K88, Salmonella choleraesuis and Bifidobacteria pseudolongum of porcine gastrointestinal origin. J. Anim. Sci., 76: 551-556.

Mikcha, J.M., M.G. Freire, M.L. Macedo, T. Yano and A.J.P. Ferreira, 2006. Characterization of a nonfimbrial Mannose-Sensitive Hemagglutinin (MSH) produced by Salmonella enteric serovar enteritidis. Comp. Immunol. Microbiol. Infect. Dis., 29: 301-314.

Neubauer, C., M. de Souza-Pilz, A.M. Bojesen, M. Bisgaard and M. Hess, 2009. Tissue distribution of haemolytic Gallibacterium anatis isolates in laying birds with reproductive disorders. Avian Pathol., 38: 1-7.

Ramirez, S., A. Zepeda, V. Vega, V. Morales, L. Perez, S. Diaz and V.E. Soriano, 2007. In vitro adhesion assays of Gallibacterium to chicken tracheal or oviductal epithelial cells. Proceedings of the 144th American Veterinary Medical Association, (AVMA'07), American Association of Avian Pathology, Washington, DC., USA.

Rocha-De-Souza, C.M., A.V. Colombo, R. Hirata, A.L. Mattos-Guaraldi and L.H. Monteiro-Leal et al., 2001. Identification of a $43-\mathrm{kDa}$ outer-membrane protein as an adhesin in Aeromonas caviae. J. Med. Microbiol., 50: 313-319. 
Sarrn, A., R. Virkola, J. Hacker and T.K. Korhonen, 1999. The cellular form of human fibronectin as an adhesion target for the $\mathrm{S}$ fimbriae of meningitisassociated Escherichia coli. Infect. Immunity, 67: 2671-2676.

Soriano, V.E., P.J. Blackall, S.M. Dabo, G. Tellez, G.A. Garcia-Delgado and R.P. Fernandez, 2001. Serotyping of Haemophilus paragallinarum isolates from Mexico by the Kume hemagglutinin scheme. Avian Dis., 45: 680-683.

Temple, L.M., A.A. Weiss, K.E. Walker, H.J. Barnes and V.L. Christensen et al., 1998. Bordetella avium virulence measured in vivo and in vitro. Infect. Immunity, 66: 5244-5251.
Yamaguchi, T., M. Kobayashi, S. Masaki and Y. Iritani, 1993. Isolation and characterization of a Haemophilus paragallinarum mutant that lacks a hemagglutinating antigen. Avian Dis., 37: $970-976$.

Zepeda, A., S. Ramirez, V. Vega, V. Morales and M. Talavera et al., 2009. Hemagglutinating activity of Gallibacterium strains. Avian Dis., 53: 115-118.

Zepeda, V.A., N.L. Calderon-Apodaca, M.L. Paasch, P.G. Martin, D.A. Paredes, S. Ramirez-Apolinar and E. Soriano-Vargas, 2010. Histopathological findings in chickens experimentally infected with Gallibacterium anatis by nasal instillation. Avian Dis., 54: 1306-1309. 